\title{
Commentary: Endoscopic Transaxillary Versus Inframammary Approaches for Breast Augmentation Using Shaped Implants: A Matched Case-Control Study
}

\author{
Ruth Maria Graf $^{1}(\mathbb{D}) \cdot$ Maria Cecilia Closs Ono $^{1}$
}

Received: 10 February 2019/Accepted: 14 February 2019/Published online: 25 February 2019

(C) Springer Science+Business Media, LLC, part of Springer Nature and International Society of Aesthetic Plastic Surgery 2019

Level of Evidence $V$ This journal requires that authors assign a level of evidence to each article. For a full description of these Evidence-Based Medicine ratings, please refer to the Table of Contents or the online Instructions to Authors www.springer.com/00266.

We would like to congratulate the authors regarding the article comparing transaxillary and inframammary approaches for breast augmentation. Even though there is a longer learning curve for the axillary approach, surgeons need to get experience with this technique to reach the demand of young patients, who prefer this surgical option to have no scar at their breasts.

Transaxillary breast augmentation has been considered a more technically difficult approach, especially when associated with shaped implants [1]. This study has compared the use of the inframammary and endoscopic transaxillary approaches for shaped implants in breast augmentation surgeries. The results show that both options of surgical approaches are comparable, and one is not inferior to the other.

For many years, many plastic surgeons have criticized the axillary approach and emphasized the limits of this procedure, questioning the reliability in attaining precise

Electronic supplementary material The online version of this article (https://doi.org/10.1007/s00266-019-01334-4) contains supplementary material, which is available to authorized users.

Ruth Maria Graf

ruthgraf@uol.com.br

1 Federal University of Paraná, Curitiba, Brazil positioning of the anatomic implant in the lower pole of the breast [2]. However, since the early 2000s Graf has pointed out the feasibility and safety of the use of transaxillary approach in selected cases for breast augmentation [3, 4].

Some technical details remain important to be aware of during the procedure:

- Making an adequate implant pocket, paying attention to reach adequately the inferior breast pole, avoiding incorrect positioning of the implant.

- When the patient has a short vertical distance between the nipple areola complex and the inframammary fold, it is important to make a new inframammary fold, undermining the implant pocket more inferiorly. This is a great advantage of the transaxillary approach. You do not have to fix the inframammary fold (local of the incision in case of the inframammary approach). You can undermine inferiorly until you feel that the pocket is well placed, and the implant fits the inferior pole adequately.

- During insertion of the implant, the surgeon can use a very simple maneuver, in order to rotate the shaped implant easily.

- Recently the funnel device has been used to help introduce the implant inside the pocket with a smaller incision and without touching the implant, avoiding biofilm formation (see videos: 1 through the axillae and 2 through the inframammary approaches).

- With the use of long retractors and fiber optical devices, the necessity of endoscopy is not even more imperative.

\section{Compliance with Ethical Standards}

Conflicts of interest The authors declare that they have no conflicts of interest to disclose. 
Human and Animal Rights This article does not contain any studies with human participants or animals performed by any of the authors.

Informed Consent For this type of study, informed consent is not required.

\section{References}

1. Sim H, Sun S (2015) Transaxillary endoscopic breast augmentation with shaped gel implants. Aesthet Surg J 35(8):952-961. https://doi.org/10.1093/asj/sjv104

2. Munhoz AM, Gemperli R, Goes JCS (2015) Transaxillary subfascial augmentation mammaplasty with anatomic form- stable silicone implants. Clin Plast Surg 42(4):565-584. https:// doi.org/10.1016/j.cps.2015.06.016

3. Graf RM, Bernardes A, Rippel R, Araujo LRR, Damasio RCC, Auersvald A (2003) Subfascial breast implant: a new procedure. Plast Reconstr Surg 111(2):904-908. https://doi.org/10.1097/01. PRS.0000041601.59651.15

4. Graf RM, Bernardes A, Auersvald A, Damasio RCC (2000) Subfascial endoscopic transaxillary augmentation mammaplasty. Aesthet Plast Surg 24(3):216-220. https://doi.org/10.1007/ s002660010036

Publisher's Note Springer Nature remains neutral with regard to jurisdictional claims in published maps and institutional affiliations. 